\title{
EDITORIAL
}

\section{MIGRATIONS AND SECURITY ON THE OLD CONTINENT}

It has been two years since the European migrant crisis. In autumn 2015, Europe was flooded by a refugee wave that people neither expected nor imagined. It was a surprise in every way. Modern technology, reputable institutions, and leading global experts from different fields did not anticipate what happened. The European legal order, human rights, the Schengen regime, and the ideas of the West dissolved quickly and left people faced with a naked reality.

Where are the refugees now, how many are there, and how do they feel? How did the refugee crisis affect the national security system and the common European defence and security policy? The media rarely reports on this now, two years later. Instead, there is much talk of terrorist attacks in European cities, the UK's exit from the European Union, the US President, Donald Trump, and the Korean rockets that ruffle the Japanese sea.

Years ago, Samuel P. Huntington wrote a book The Clash of Civilizations. It was published in Slovenia in 2005. His assumption was that the main reason for the clash of nations in the future would be their cultural and religious identity. He predicted that the greatest threat would be extreme terrorism. Different ideologies would be replaced by self-oriented individuals, who would no longer be concerned about the common good, but focused on themselves and their benefits. The absence of ideologies would be replaced by a return to ancient traditions. Responses to Huntington's work were very different; some were enthusiastic, others sceptical. We can, however, conclude that his theory, first presented in 1992, was confirmed in the case of the war in the Western Balkans. When the ideology of former Yugoslavia died, the nations and nationalities returned to their roots, which resulted in a war that claimed the lives of many people. 
Robert D. Kaplan also wrote about the fact that the Western Balkans is a crossroads of different cultures. The most famous of his works is Balkan Ghosts, in which Kaplan examines in detail the historical and cultural turbulence in the immediate neighbourhood of the cradle of Western civilization, which has been the driving force behind the development of the West for the past two thousand years.

This issue of Contemporary Military Challenges is therefore interested in what is new on the Old Continent, emphasizing security, defence and the military.

In his article Geostrategic Shifts in Contemporary Europe, Uroš Tovornik examines the geostrategic significance of the relationships between France, Germany and the United Kingdom, the countries that shaped the fate of Europe in the past. With the UK's decision to leave the European Union, the former classic geostrategic triangle can now turn into other decisive geostrategic links which could greatly change the Old Continent.

József Kis Benedek writes about the consequences of events in North Africa and the Middle East. In the recent past, some authors have wondered whether the Arab Spring would be followed by Arab Winter; however, what followed was the European migrant crisis and the escalation of terrorist attacks in Europe. In his article Challenges Posed to the European Union by the Iraqi, Syrian and Libyan Crises, the author focuses on the participation of foreign fighters in crisis areas, coming from Europe to aid.

Economic Intelligence: an Inevitable Choice is the title of an article written by Laris Gaiser. It stresses the urgent need for Slovenia to devote greater attention to this area in order to ensure greater benefits for its citizens. Slovenia has come a long way since 1991, but modern security guidelines stipulate that, besides classic tasks in the intelligence and security field, economic intelligence is also important. What is the situation in Slovenia and what else should we do?

For several years, the Slovenian Armed Forces have been involved in the international operation and mission in Bosnia and Herzegovina. Slovenia is accompanied by many other European Union member states, ensuring peace and order in the country. How long will this go on, and how successful are the international security forces in the area? It is this and some other questions that the authors Ivana Boštjančič Pulko, Johanna Suhonen and Kari Sainio try to answer in the article Assessing the Planning and Implementation of the EU Missions and Operations: Case Study of EUFOR Althea in Bosnia and Herzegovina.

Cybernetics, cyberspace and cyber attacks are commonly known terms of which much has been heard and read about recently. How well do we really know these terms? Is there a legal basis at the national level and how is this field regulated in the international environment? This is a challenge requiring strategic and concrete answers. One of the possible answers can be found in the article Legality of LowIntensity Cyber Operations under International Law by Pika Šarf. 
Military aviation is an integral part of the modern armed forces. Slovenian military aviation is relatively young and has, in its short history, experienced several development phases, both in the field of aeronautics and in the organizational military sense. The quality of cooperation of Slovenian military pilots in international operations, missions, and international military exercises testifies that we are on the right track. But how to proceed? In his article, Characteristics of the Slovenian Armed Forces Air Force: Now and 20 Years in the future, the author Mitja Lipovšek refers to the idea that history is a debate of the past with the present for the future.

We wish you an interesting read, and invite you to also participate as authors of articles. 